Check for updates

Cite this: RSC Adv., 2019, 9, 18042

Received 6th April 2019

Accepted 12th May 2019

DOI: $10.1039 / c 9 r a 02584 g$

rsc.li/rsc-advances

\title{
Infrared and Raman spectra of $\mathrm{Bi}_{2} \mathrm{O}_{2} \mathrm{X}$ and $\mathrm{Bi}_{2} \mathrm{OX}_{2}$ $(X=S, S e$, and $\mathrm{Te}$ ) studied from first principles calculations $\uparrow$
}

\author{
Yao-Di Xu, ${ }^{\text {a }}$ Cong Wang, ${ }^{a}$ Yang-Yang Lv, ${ }^{a}$ Y. B. Chen, ${ }^{b}$ Shu-Hua Yao ${ }^{\text {acd }}$ \\ and Jian Zhou (iD *acd
}

\begin{abstract}
The bismuth oxychalcogenide compounds contain many different kinds of materials, such as $\mathrm{Bi}_{2} \mathrm{O}_{2} \mathrm{X}$ and $\mathrm{Bi}_{2} \mathrm{OX}_{2}(\mathrm{X}=\mathrm{S}, \mathrm{Se}$, and $\mathrm{Te}$ ). These materials have different but similar layered crystal structures and exhibit various interesting physical properties. Here, we have theoretically investigated their Raman and infrared spectra by first principles calculations based on density functional theory. It is found that in $\mathrm{Bi}_{2} \mathrm{O}_{2} \mathrm{Se}$ the calculated frequency of the $\mathrm{A}_{1 \mathrm{~g}}$ Raman active mode is in good agreement with the experimental measurements while the other three modes are ambiguous or not observed yet. The Raman and infrared spectra of other materials are also presented and need further confirmation. Our work provides the structural fingerprints of these materials, which could be helpful in identifying the crystal structures in future experiments.
\end{abstract}

\section{Introduction}

In recent years, bismuth oxychalcogenide materials $\mathrm{Bi}-\mathrm{O}-\mathrm{X}(\mathrm{X}=$ $\mathrm{S}$, Se, and $\mathrm{Te}$ ) have attracted more and more attention. Among these materials, $\mathrm{Bi}_{2} \mathrm{O}_{2} \mathrm{Se}$, synthesized more than forty years ago, ${ }^{1}$ is one of the most studied materials and has now become a very hot topic due to its various and interesting physical properties. First, $\mathrm{Bi}_{2} \mathrm{O}_{2} \mathrm{Se}$ was suggested to be a good thermoelectric material. ${ }^{2-7}$ In 2010, Ruleova et al. reported the thermoelectric properties of $\mathrm{Bi}_{2} \mathrm{O}_{2}$ Se and they found that $\mathrm{Bi}_{2} \mathrm{O}_{2} \mathrm{Se}$ is an n-type semiconductor with a very low thermal conductivity and a relatively high figure of merit $Z T$ about 0.2 at $800 \mathrm{~K}^{2}$ Several theoretical works were also conducted to explore its thermoelectric properties. ${ }^{8-11}$ Second, $\mathrm{Bi}_{2} \mathrm{O}_{2}$ Se has an ultrahigh electron mobility. ${ }^{12-17}$ An earlier work in 2012 found that the room temperature Hall mobility of $\mathrm{Bi}_{2} \mathrm{O}_{2} \mathrm{Se}$ single crystal was on the order of $300 \mathrm{~cm}^{2} \mathrm{~s}^{-1} \mathrm{~V}^{-1} \cdot{ }^{12}$ Recently, it was found that the low temperature (about $2 \mathrm{~K}$ ) Hall mobility can reach more than $2.0 \times 10^{4} \mathrm{~cm}^{2} \mathrm{~s}^{-1} \mathrm{~V}^{-1}$ in $\mathrm{Bi}_{2} \mathrm{O}_{2} \mathrm{Se}$ thin film ${ }^{13-15}$ and $4.0 \times 10^{4} \mathrm{~cm}^{2}$ $\mathrm{s}^{-1} \mathrm{~V}^{-1}$ in $\mathrm{Bi}_{2} \mathrm{O}_{2} \mathrm{Se}$ single crystal. ${ }^{16}$ Very recently, we have

${ }^{a}$ National Laboratory of Solid State Microstructures and Department of Materials Science and Engineering, Nanjing University, Nanjing 210093, China. E-mail: zhoujian@nju.edu.cn

${ }^{b}$ National Laboratory of Solid State Microstructures and Department of Physics, Nanjing University, Nanjing 210093, China

'Collaborative Innovation Center of Advanced Microstructures, Nanjing University, Nanjing, 210093, China

${ }^{d}$ Jiangsu Key Laboratory of Artificial Functional Materials, Nanjing University, Nanjing 210093, China

$\dagger$ Electronic supplementary information (ESI) available. See DOI: $10.1039 / \mathrm{c} 9 \mathrm{ra02584g}$ observed a superior Hall mobility of $2.2 \times 10^{5} \mathrm{~cm}^{2} \mathrm{~s}^{-1} \mathrm{~V}^{-1}$ at $2 \mathrm{~K}$ in a high quality $\mathrm{Bi}_{2} \mathrm{O}_{2} \mathrm{Se}$ single crystal. ${ }^{17}$ The high mobility in $\mathrm{Bi}_{2} \mathrm{O}_{2} \mathrm{Se}$ is possibly due to the self-modulation doping, i.e. the electron donor states lie above the lowest conduction band, not in the middle of the band gap. ${ }^{18}$ Furthermore, high mobility usually induces a large magnetoresistance (MR), ${ }^{19}$ which was also observed in $\mathrm{Bi}_{2} \mathrm{O}_{2}$ Se. A longitudinal MR of about $600 \%$ (at 15 Tesla and $2 \mathrm{~K}$ ) and $9000 \%$ (at 9 Tesla and $2 \mathrm{~K}$ ) in $\mathrm{Bi}_{2} \mathrm{O}_{2} \mathrm{Se}$ single crystals was observed in two recent experiments. ${ }^{16,17}$ Third, due to its high mobility and suitable band gap (about 0.8 eV), $\mathrm{Bi}_{2} \mathrm{O}_{2} \mathrm{Se}$ was used in optoelectronic devices and infrared (IR) photo-detectors. ${ }^{20-22}$

$\mathrm{Bi}_{2} \mathrm{O}_{2} \mathrm{Te}$ has the same crystal structure as that of $\mathrm{Bi}_{2} \mathrm{O}_{2} \mathrm{Se}$, but it is much less studied. Luu and Vaqueiro found that $\mathrm{Bi}_{2} \mathrm{O}_{2} \mathrm{Te}$ ceramics is an n-type semiconductor with a smaller band gap $(0.23 \mathrm{eV})$, electron mobility $\left(47 \mathrm{~cm}^{2} \mathrm{~s}^{-1} \mathrm{~V}^{-1}\right.$ at room temperatures), and $Z T$ (0.13 at $573 \mathrm{~K}$ ), compared with those of $\mathrm{Bi}_{2} \mathrm{O}_{2} \mathrm{Se}^{23}$ The similar compound $\mathrm{Bi}_{2} \mathrm{O}_{2} \mathrm{~S}$ is also less studied. $\mathrm{Bi}_{2} \mathrm{O}_{2} \mathrm{~S}$ was first synthesized in 1984 and it has a different crystal structure to that of $\mathrm{Bi}_{2} \mathrm{O}_{2} \mathrm{Se}^{24}$ There are only a few studies on its optical properties. ${ }^{25-27}$ For example, it was found that $\mathrm{Bi}_{2} \mathrm{O}_{2} \mathrm{~S}$ has an indirect band gap of $1.12 \mathrm{eV}$ and it is an excellent photoelectric material. ${ }^{27}$

On the other hand, there is another kind of bismuth oxychalcogenides $\mathrm{Bi}_{2} \mathrm{OX}_{2}(\mathrm{X}=\mathrm{S}$, Se, and Te), which all share the same tetragonal lattice system. Among them, $\mathrm{Bi}_{2} \mathrm{OS}_{2}$ has been experimentally synthesized recently and it was a candidate as an optoelectronic material in the near-IR region. ${ }^{28}$ First principles calculations indicated that the two-dimensional $\mathrm{Bi}_{2} \mathrm{OS}_{2}$ nanosheet possesses a direct band gap and an ultrahigh electron mobility (up to $2.6 \times 10^{4} \mathrm{~cm}^{2} \mathrm{~s}^{-1} \mathrm{~V}^{-1}$ ). ${ }^{29}$ To the best of our knowledge, $\mathrm{Bi}_{2} \mathrm{OSe}_{2}$ and $\mathrm{Bi}_{2} \mathrm{OTe}_{2}$ have not been synthesized 
experimentally. However, first principles calculations showed that they have the same crystal structure as that of $\mathrm{Bi}_{2} \mathrm{OS}_{2} \cdot{ }^{30}$ In particular, the calculated electron and hole effective mass of $\mathrm{Bi}_{2} \mathrm{OX}_{2}$ is very small. For example, the effective mass of $\mathrm{Bi}_{2} \mathrm{OTe}_{2}$ is only 0.02 and 0.012 for electron and hole. ${ }^{30}$ Another theoretical study indicated that $\mathrm{Bi}_{2} \mathrm{OX}_{2}$ materials show promising characteristics in applications for solar cells and thermoelectric devices. $^{31}$

Besides $\mathrm{Bi}_{2} \mathrm{O}_{2} \mathrm{X}$ and $\mathrm{Bi}_{2} \mathrm{OX}_{2}$, the first $\mathrm{BiS}_{2}$ family superconductor $\mathrm{Bi}_{4} \mathrm{O}_{4} \mathrm{~S}_{3}$ was studied over the past few years. ${ }^{32,33}$ Later, it was found that $\mathrm{Bi}_{4} \mathrm{O}_{4} \mathrm{~S}_{3}$ is a mixture of the two phases, $\mathrm{Bi}_{2} \mathrm{OS}_{2}$ and $\mathrm{Bi}_{3} \mathrm{O}_{2} \mathrm{~S}_{3} \cdot{ }^{34}$ The former is non-superconducting, while the latter is superconducting. ${ }^{34-36}$

Therefore, we can see that the $\mathrm{Bi}-\mathrm{O}-\mathrm{X}$ system contains many kinds of materials with various interesting physical properties. From the experimental point of view, it is of course very important to identify the structure of the grown crystal from the many similar Bi-O-X materials. In this regard, Raman and IR spectra are convenient and powerful methods to provide the structural fingerprints of materials. However, we find that the Raman and IR studies of these materials are quite lacking. Only a few works about the Raman spectra of $\mathrm{Bi}_{2} \mathrm{O}_{2}$ Se and $\mathrm{Bi}_{2} \mathrm{O}_{2}$ Te have been reported until now. ${ }^{\mathbf{1 4 , 1 6 , 3 7 , 3 8}}$ For this reason, we have systematically calculated the phonon, irreducible representations, Raman and IR spectra, vibrational eigenvectors of optical phonons, and polarized Raman configurations of six materials: $\mathrm{Bi}_{2} \mathrm{O}_{2} \mathrm{X}$ and $\mathrm{Bi}_{2} \mathrm{OX}_{2}$. We mainly present the results of $\mathrm{Bi}_{2} \mathrm{O}_{2} \mathrm{Se}$ and $\mathrm{Bi}_{2} \mathrm{O}_{2}$ Te since they can be compared with other works. The Raman and IR spectra of the other four materials are also given briefly and could be referenced by future experiments.

\section{Computational details}

The vibrational properties of $\mathrm{Bi}_{2} \mathrm{O}_{2} \mathrm{X}$ and $\mathrm{Bi}_{2} \mathrm{OX}_{2}(\mathrm{X}=\mathrm{S}$, Se, and $\mathrm{Te})$ are calculated by density functional theory (DFT) implemented in the Vienna ab initio simulation package (VASP). ${ }^{39,40}$ The projected augmented wave method $^{\mathbf{4 1 , 4 2}}$ and the generalized gradient approximation with the Perdew-Burke-Ernzerhof exchange-correlation functional ${ }^{43}$ are used. The DFT-D3 $\operatorname{method}^{\mathbf{4 4 , 4 5}}$ is used to correct the van der Waals interactions in these layered materials. The plane-wave cutoff energy is $520 \mathrm{eV}$ for all materials. Both the internal atomic positions and the lattice constants are allowed to relax until the maximal residual Hellmann-Feynman forces on atoms are smaller than $0.002 \mathrm{eV}^{-1}$. The $k$-mesh is $8 \times 8 \times 2$ for $\mathrm{Bi}_{2} \mathrm{O}_{2} \mathrm{~S}$ and $\mathrm{Bi}_{2} \mathrm{OX}_{2}$ and $8 \times 8 \times 8$ for $\mathrm{Bi}_{2} \mathrm{O}_{2}$ Se and $\mathrm{Bi}_{2} \mathrm{O}_{2}$ Te. The Phonopy package ${ }^{46}$ is used to calculate the phonon frequencies, eigenvectors and irreducible representations of the materials. The crystal structures and eigenvectors are plotted by the VESTA program. ${ }^{\mathbf{4}}$

The IR and Raman activity of phonon modes can be analyzed by their irreducible representations. However their intensities need additional calculations. The IR intensity of a phonon mode is given by the corresponding oscillator strength: ${ }^{48}$

$$
f(\nu)=\sum_{\alpha}\left|\sum_{s \beta} Z_{\alpha \beta}^{*}(s) e_{\beta}(s, \nu)\right|^{2}
$$

where the $e_{\beta}(s, v)$ is the normalized vibrational eigenvector of the $\nu$ th phonon mode of the sth atom in the unit cell. $\alpha$ and $\beta$ are the Cartesian coordinates: $x, y, z . Z_{\alpha \beta}^{*}(s)$ is the Born effective charge tensor of the sth atom. The Born effective charge tensor and the phonon eigenvectors are calculated by the density functional perturbation theory (DFPT) implemented in the VASP code. This method has been applied to different material systems. ${ }^{48-51}$

The off-resonance Raman intensity of a phonon mode can be estimated by calculating the derivative of the macroscopic dielectric tensor with respect to the normal mode coordinate: ${ }^{22}$

$$
I_{\operatorname{Raman}}(\nu) \propto \frac{\partial \varepsilon^{\infty}}{\partial Q(\nu)}
$$

where the $\varepsilon^{\infty}$ is the macroscopic high-frequency dielectric constant and $Q(v)$ is the normal mode coordinate of the $\nu$ th phonon mode. In practice, the derivative is replaced by the central difference based on the macroscopic dielectric matrix evaluated at positive and negative displacement along the phonon mode $Q(v)$. The macroscopic dielectric matrix is also calculated by the DFPT method in the VASP code. This method has also been applied to different material systems. ${ }^{53,54}$

\section{Results and discussions}

\subsection{Crystal structures of $\mathrm{Bi}_{2} \mathrm{O}_{2} \mathrm{X}$ and $\mathrm{Bi}_{2} \mathrm{OX}_{2}$}

The six materials $\mathrm{Bi}_{2} \mathrm{O}_{2} \mathrm{X}$ and $\mathrm{Bi}_{2} \mathrm{OX}_{2}(\mathrm{X}=\mathrm{S}$, Se, and Te) have three different crystal structures. $\mathrm{Bi}_{2} \mathrm{O}_{2} \mathrm{~S}$ belongs to a primitive orthorhombic lattice with a space group Pnnm (no. 58), ${ }^{24}$ while $\mathrm{Bi}_{2} \mathrm{O}_{2} \mathrm{Se}$ and $\mathrm{Bi}_{2} \mathrm{O}_{2}$ Te possess a body centered tetragonal lattice with a space group $I 4 / \mathrm{mmm}$ (no. 139). ${ }^{1,13,23}$ On the other hand, $\mathrm{Bi}_{2} \mathrm{OX}_{2}$ have a primitive tetragonal lattice with a space group $P 4 /$ $\mathrm{nmm}$ (no. 129) ${ }^{28,55}$ All the materials show layered structures as shown in Fig. 1. $\mathrm{Bi}_{2} \mathrm{O}_{2} \mathrm{X}$ consists of two $\mathrm{Bi}_{2} \mathrm{O}_{2}$ and two $\mathrm{X}$ layers, while $\mathrm{Bi}_{2} \mathrm{OX}_{2}$ is composed of one $\mathrm{Bi}_{2} \mathrm{O}_{2}$ and two $\mathrm{BiX}_{2}$ layers in a unit cell. Although the symmetries of $\mathrm{Bi}_{2} \mathrm{O}_{2} \mathrm{~S}$ and $\mathrm{Bi}_{2} \mathrm{O}_{2}$ Se are totally different, the structure of $\mathrm{Bi}_{2} \mathrm{O}_{2} \mathrm{~S}$ is a slightly distorted form of $\mathrm{Bi}_{2} \mathrm{O}_{2} \mathrm{Se}^{24}$ Therefore, the difference between the two structures shown in Fig. 1(a) and (b) is hardly visible to the naked eye. All the structures shown in Fig. 1 contain ten atoms in the unit cell. However, $\mathrm{Bi}_{2} \mathrm{O}_{2} \mathrm{Se}$ and $\mathrm{Bi}_{2} \mathrm{O}_{2}$ Te shown in

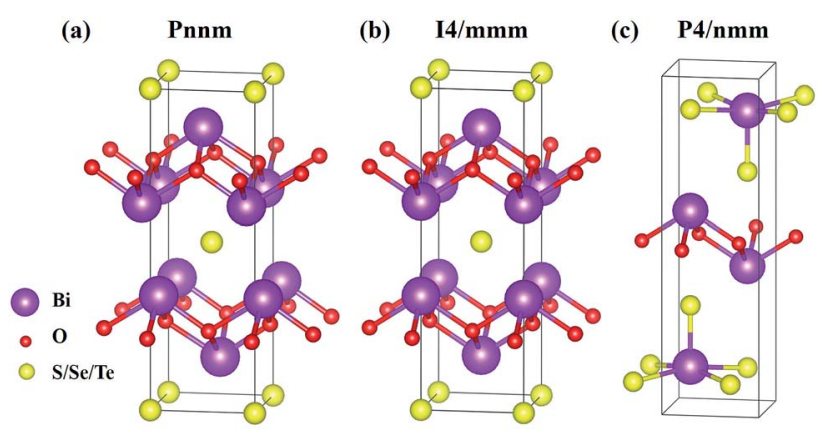

Fig. 1 Layered crystal structures of (a) orthorhombic $\mathrm{Bi}_{2} \mathrm{O}_{2} \mathrm{~S}$, (b) tetragonal $\mathrm{Bi}_{2} \mathrm{O}_{2} \mathrm{Se}$ and $\mathrm{Bi}_{2} \mathrm{O}_{2} \mathrm{Te}$, (c) tetragonal $\mathrm{Bi}_{2} \mathrm{OS}_{2}, \mathrm{Bi}_{2} \mathrm{OSe}_{2}$, and $\mathrm{Bi}_{2} \mathrm{OTe}_{2}$. The purple, red, and yellow balls represent $\mathrm{Bi}, \mathrm{O}$, and $\mathrm{S} / \mathrm{Se} / \mathrm{Te}$ atoms respectively. 
Table 1 Calculated lattice constants of $\mathrm{Bi}_{2} \mathrm{O}_{2} \mathrm{X}$ and $\mathrm{Bi}_{2} \mathrm{OX}_{2}(\mathrm{X}=\mathrm{S}$, Se, and $\mathrm{Te}$ ) in the unit of $\AA$. Other theoretical and experimental results are also given for comparison

\begin{tabular}{|c|c|c|c|c|c|}
\hline Symmetry & Material & Reference & $a$ & $b$ & $c$ \\
\hline \multirow[t]{3}{*}{ Orthorhombic Pnnm } & \multirow[t]{3}{*}{$\mathrm{Bi}_{2} \mathrm{O}_{2} \mathrm{~S}$} & This work & 3.837 & 3.848 & 11.94 \\
\hline & & Experiment $^{24}$ & 3.840 & 3.874 & 11.92 \\
\hline & & Theory $^{30}$ & 3.87 & 3.89 & 11.99 \\
\hline \multirow[t]{7}{*}{ Tetragonal $\mathrm{I} 4 / \mathrm{mmm}$} & \multirow[t]{4}{*}{$\mathrm{Bi}_{2} \mathrm{O}_{2} \mathrm{Se}$} & This work & 3.891 & 3.891 & 12.20 \\
\hline & & Experiment $^{1}$ & 3.891 & 3.891 & 12.21 \\
\hline & & Experiment $^{13}$ & 3.88 & 3.88 & 12.16 \\
\hline & & Theory $^{30}$ & 3.91 & 3.91 & 12.38 \\
\hline & \multirow[t]{3}{*}{$\mathrm{Bi}_{2} \mathrm{O}_{2} \mathrm{Te}$} & This work & 3.984 & 3.984 & 12.65 \\
\hline & & Experiment $^{23}$ & 3.980 & 3.980 & 12.70 \\
\hline & & Theory $^{30}$ & 4.01 & 4.01 & 12.63 \\
\hline \multirow{8}{*}{ Tetragonal $P 4 / \mathrm{nmm}$} & \multirow{4}{*}{$\mathrm{Bi}_{2} \mathrm{OS}_{2}$} & This work & 3.950 & 3.950 & 13.84 \\
\hline & & Experiment $^{28}$ & 3.961 & 3.961 & 13.80 \\
\hline & & Experiment $^{55}$ & 3.964 & 3.964 & 13.83 \\
\hline & & Theory $^{30}$ & 3.96 & 3.96 & 13.69 \\
\hline & \multirow[t]{2}{*}{$\mathrm{Bi}_{2} \mathrm{OSe}_{2}$} & This work & 4.044 & 4.044 & 14.56 \\
\hline & & Theory $^{30}$ & 4.05 & 4.05 & 14.46 \\
\hline & \multirow[t]{2}{*}{$\mathrm{Bi}_{2} \mathrm{OTe}_{2}$} & This work & 4.193 & 4.193 & 15.81 \\
\hline & & Theory $^{30}$ & 4.17 & 4.17 & 15.99 \\
\hline
\end{tabular}

Fig. 1(b) is a conventional cell, which in fact contains two primitive cells.

It is noted that among the six materials, to the best of our knowledge, $\mathrm{Bi}_{2} \mathrm{OSe}_{2}$ and $\mathrm{Bi}_{2} \mathrm{OTe}_{2}$ have not been synthesized experimentally. Their crystal structures are predicted to be the same as that of $\mathrm{Bi}_{2} \mathrm{OS}_{2}$ by first principles calculations. ${ }^{30}$

The calculated lattice constants in this work with the DFT-D3 correction are listed in Table 1. It is obvious that our calculated results are well consistent with the experimental measurements with the largest difference less than $1 \%$. Our results are also in good agreement with other theoretical work..$^{30}$

With the optimized structures, the zone-centered phonon modes, irreducible representations, IR and Raman spectra of the six materials are calculated. In the following subsections, we first present the detailed results of $\mathrm{Bi}_{2} \mathrm{O}_{2} \mathrm{Se}$ and $\mathrm{Bi}_{2} \mathrm{O}_{2} \mathrm{Te}$ since both materials have the same crystal structure and the Raman spectrum of $\mathrm{Bi}_{2} \mathrm{O}_{2} \mathrm{Se}$ is better studied than other materials. Then the brief results of $\mathrm{Bi}_{2} \mathrm{O}_{2} \mathrm{~S}$ and $\mathrm{Bi}_{2} \mathrm{OX}_{2}$ are also given.

\subsection{I4/mmm tetragonal $\mathrm{Bi}_{2} \mathrm{O}_{2} \mathrm{Se}$ and $\mathrm{Bi}_{2} \mathrm{O}_{2} \mathrm{Te}$}

The calculated zone-centered optical phonon frequencies of $\mathrm{Bi}_{2} \mathrm{O}_{2} \mathrm{Se}$ and $\mathrm{Bi}_{2} \mathrm{O}_{2}$ Te are listed in Table 2. The highest phonon frequency of $\mathrm{Bi}_{2} \mathrm{O}_{2} \mathrm{Se}$ is about $433.3 \mathrm{~cm}^{-1}$, while it is only $396.1 \mathrm{~cm}^{-1}$ in $\mathrm{Bi}_{2} \mathrm{O}_{2} \mathrm{Te}$ due to the heavier atom mass. $\mathrm{Bi}_{2} \mathrm{O}_{2} \mathrm{Se}$ and $\mathrm{Bi}_{2} \mathrm{O}_{2} \mathrm{Te}$ have the same space group of $14 / \mathrm{mmm}$ (point group $D_{4 \mathrm{~h}}$ ), and their irreducible representations at the $\Gamma$ point in the Brillouin zone are:

$$
\begin{gathered}
\Gamma_{\text {acoustic }}=\mathrm{E}_{\mathrm{u}}+\mathrm{A}_{2 \mathrm{u}} \\
\Gamma_{\text {optic }}=2 \mathrm{E}_{\mathrm{u}}+2 \mathrm{~A}_{2 \mathrm{u}}+2 \mathrm{E}_{\mathrm{g}}+\mathrm{A}_{1 \mathrm{~g}}+\mathrm{B}_{1 \mathrm{~g}}
\end{gathered}
$$

There are five atoms in the primitive cell of $\mathrm{Bi}_{2} \mathrm{O}_{2} \mathrm{Se}$, therefore we can find three acoustic and twelve optical modes. These irreducible representations are also assigned to each optical phonon mode as shown in Table 2. According to the character table of the $D_{4 \mathrm{~h}}$ point group, the $\mathrm{E}_{\mathrm{u}}$ and $\mathrm{A}_{2 \mathrm{u}}$ modes are IR active, while the $\mathrm{E}_{\mathrm{g}}, \mathrm{A}_{1 \mathrm{~g}}$, and $\mathrm{B}_{1 \mathrm{~g}}$ modes are Raman active in $\mathrm{Bi}_{2} \mathrm{O}_{2} \mathrm{Se}$ and $\mathrm{Bi}_{2} \mathrm{O}_{2}$ Te. Therefore, both materials have four Raman active (two double degenerated $\mathrm{E}_{\mathrm{g}}$ mode and two non-degenerated $\mathrm{A}_{1 \mathrm{~g}}$ and $\mathrm{B}_{1 \mathrm{~g}}$ modes) and four IR active modes (two double degenerated $\mathrm{E}_{\mathrm{u}}$ modes and two non-degenerated $\mathrm{A}_{2 \mathrm{u}}$ modes), as indicated in Table 2 .

Recently, there have been two joint experimental and theoretical works by Pereira et al..$^{37}$ and Cheng et al. ${ }^{38}$ in which the phonon frequencies of $\mathrm{Bi}_{2} \mathrm{O}_{2} \mathrm{Se}$ and $\mathrm{Bi}_{2} \mathrm{O}_{2}$ Te are also calculated. We listed their data in Table 2 for comparison. It is found that most of the calculated frequencies are in good agreement with ours, except for the two high-frequency IR active modes $\left(\mathrm{E}_{\mathrm{u}}\right.$ and $\mathrm{A}_{2 \mathrm{u}}$ ) in $\mathrm{Bi}_{2} \mathrm{O}_{2} \mathrm{Se}$, which have a maximal discrepancy of about $25 \mathrm{~cm}^{-1}$. Phonon frequencies depend on the second derivative of the total energy, therefore the accuracy of the phonon calculation is usually not as good as the ones of the total energy calculations. Many parameters, such as the exchange-correlation functional, will affect the theoretical phonon frequencies. Therefore, we think such differences between these works are acceptable in phonon calculations.

We also illustrate the vibrational eigenvectors of $\mathrm{Bi}_{2} \mathrm{O}_{2} \mathrm{Se}$ in Fig. 2. It is found that the two low-frequency Raman active modes $\left(\mathrm{E}_{\mathrm{g}}\right.$ and $\mathrm{A}_{1 \mathrm{~g}}$ ) are related to the in-plane and out-of-plane

Table 2 Calculated frequencies and Mulliken symbols of zone-centered optical phonon modes of $\mathrm{Bi}_{2} \mathrm{O}_{2} \mathrm{Se}_{\mathrm{and}} \mathrm{Bi}_{2} \mathrm{O}_{2} \mathrm{Te}$. The theoretical frequencies in other works by Pereira ${ }^{37}$ and Cheng ${ }^{38}$ are also listed for comparison. Raman or IR activity of each mode is also indicated by

\begin{tabular}{|c|c|c|c|c|c|c|}
\hline \multirow[b]{2}{*}{ Symmetry } & \multicolumn{3}{|l|}{$\underline{\mathrm{Bi}_{2} \mathrm{O}_{2} \mathrm{Se}}$} & \multicolumn{2}{|l|}{$\mathrm{Bi}_{2} \mathrm{O}_{2} \mathrm{Te}$} & \multirow[b]{2}{*}{ Activity } \\
\hline & This work & Pereira $^{37}$ & Cheng $^{38}$ & This work & Cheng. $^{38}$ & \\
\hline$E_{u}$ & 54.8 & 59.2 & & 56.4 & & IR \\
\hline $\mathrm{A}_{2 \mathrm{u}}$ & 65.0 & 64.5 & & 63.3 & & IR \\
\hline$E_{g}$ & 67.3 & 72.0 & 67.99 & 69.1 & 67.01 & Raman \\
\hline$A_{1 g}$ & 162.9 & 165.7 & 159.89 & 150.4 & 147.48 & Raman \\
\hline $\mathrm{E}_{\mathrm{u}}$ & 268.0 & 293.9 & & 243.6 & & IR \\
\hline$B_{1 g}$ & 354.3 & 369.4 & 364.02 & 336.0 & 340.33 & Raman \\
\hline$A_{2 u}$ & 377.8 & 402.8 & & 347.3 & & \\
\hline $\mathrm{E}_{\mathrm{g}}$ & 433.3 & 444.0 & 428.68 & 396.1 & 386.15 & Raman \\
\hline
\end{tabular}
"Raman" and "IR". The unit of the phonon frequency is $\mathrm{cm}^{-1}$ 

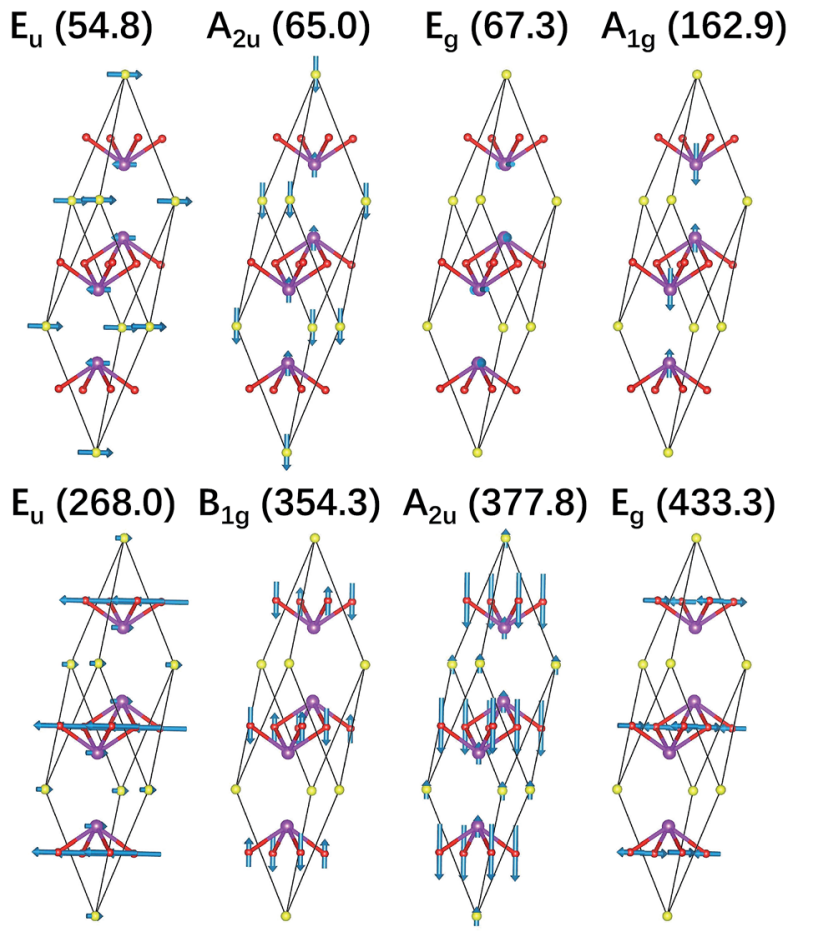

Fig. 2 Vibrational eigenvectors of the zone-centered optical phonon modes shown in the primitive cell of $\mathrm{Bi}_{2} \mathrm{O}_{2} \mathrm{Se}$. The purple, red, and yellow balls represent $\mathrm{Bi}, \mathrm{O}$, and $\mathrm{Se}$ atoms respectively.

vibrations of $\mathrm{Bi}$ atoms, respectively. While the two highfrequency Raman active modes $\left(B_{1 g}\right.$ and $\left.E_{g}\right)$ represent the outof-plane and in-plane vibrations of $\mathrm{O}$ atoms, respectively. Vibrations of Se atoms are not involved in any Raman active modes. The two low-frequency IR active modes $\left(\mathrm{E}_{\mathrm{u}}\right.$ and $\left.\mathrm{A}_{2 \mathrm{u}}\right)$ are related to the in-plane and out-of-plane vibrations of Bi and Se atoms, respectively. While the two high-frequency IR active modes $\left(E_{u}\right.$ and $\left.A_{2 u}\right)$ mainly represent the in-plane and out-ofplane vibrations of $\mathrm{O}$ atoms, respectively. The vibrational eigenvectors of $\mathrm{Bi}_{2} \mathrm{O}_{2} \mathrm{Te}$ are similar to those of $\mathrm{Bi}_{2} \mathrm{O}_{2} \mathrm{Se}$, which are not shown here.

Then we present a detailed analysis about the polarized configurations for the Raman active modes of $\mathrm{Bi}_{2} \mathrm{O}_{2} \mathrm{Se}$ and $\mathrm{Bi}_{2} \mathrm{O}_{2} \mathrm{Te}$. The Raman tensors of the $D_{4 \mathrm{~h}}$ point group can be written as:

$$
\begin{gathered}
P\left(\mathrm{E}_{\mathrm{g}}\right)=\left(\begin{array}{lll}
0 & 0 & 0 \\
0 & 0 & e \\
0 & e & 0
\end{array}\right),\left(\begin{array}{ccc}
0 & 0 & -e \\
0 & 0 & 0 \\
-e & 0 & 0
\end{array}\right) \\
P\left(\mathrm{~A}_{1 \mathrm{~g}}\right)=\left(\begin{array}{lll}
a & 0 & 0 \\
0 & a & 0 \\
0 & 0 & b
\end{array}\right) P\left(\mathrm{~B}_{1 \mathrm{~g}}\right)=\left(\begin{array}{ccc}
c & 0 & 0 \\
0 & -c & 0 \\
0 & 0 & 0
\end{array}\right)
\end{gathered}
$$

Qualitatively, the Raman intensity $I$ of a phonon mode can be calculated by the formula $I \infty\left|e_{\mathrm{i}} \cdot P \cdot e_{\mathrm{s}}\right|^{2}$, where $e_{\mathrm{i}}$ and $e_{\mathrm{s}}$ are polarization directions of the incident and scattered light and $P$ is the Raman tensor given above. In Table 3, we present the nonequivalent polarized configurations for the Raman active modes
Table 3 The right angle and back scattering geometries in the polarized configurations of Raman active modes of $\mathrm{Bi}_{2} \mathrm{O}_{2} \mathrm{Se}$ and $\mathrm{Bi}_{2} \mathrm{O}_{2} \mathrm{Te}$. The modes that can be observed in the configuration are indicated by the mark $\checkmark$

\begin{tabular}{lccc}
\hline Configurations & $\mathrm{A}_{1 \mathrm{~g}}$ & $\mathrm{~B}_{1 \mathrm{~g}}$ & $\mathrm{E}_{\mathrm{g}}$ \\
\hline$X(Y Y) Z$ & $\checkmark$ & $\checkmark$ & \\
$Z(X X) Y$ & $\checkmark$ & $\checkmark$ & \\
$X(Z Z) Y$ & $\checkmark$ & & $\checkmark$ \\
$X(Y Z) Y$ & & & $\checkmark$ \\
$Z(X Z) X$ & & $\checkmark$ & \\
$-Z(X X) Z$ & $\checkmark$ & $\checkmark$ & $\checkmark$ \\
$-Y(X X) Y$ & $\checkmark$ & & \\
$-X(Z Z) X$ & $\checkmark$ & & \\
$-X(Y Z) X$ & & & \\
& & & \\
\end{tabular}

of $\mathrm{Bi}_{2} \mathrm{O}_{2} \mathrm{Se}$ and $\mathrm{Bi}_{2} \mathrm{O}_{2}$ Te. In the configuration notation $A(B C) D, A$ and $D$ represent the propagation directions of the incident and scattered light respectively, while $B$ and $C$ represent the polarization directions of the incident and scattered light respectively. In the right angle scattering geometry, the propagation directions of the incident and scattered light are orthogonal (first five configurations in Table 3). In the back scattering geometry, the propagation directions of the incident and scattered light are anti-parallel (last four configurations in Table 3).

From Table 3, it is interesting to find that the $\mathrm{E}_{\mathrm{g}}$ mode cannot be observed with the $\mathrm{A}_{1 \mathrm{~g}}$ and $\mathrm{B}_{1 \mathrm{~g}}$ ones simultaneously under the same polarized configuration. Also, only one $A_{1 g}$ mode can be observed in the polarized configurations: $X(Z Z) Y$ or $-X(Z Z) X$. Therefore, all of the Raman active modes can be well identified under different polarized configurations. Of course, in this case, the frequencies of the four Raman active modes in $\mathrm{Bi}_{2} \mathrm{O}_{2}$ Se and $\mathrm{Bi}_{2} \mathrm{O}_{2}$ Te are well separated and therefore it is quite easy to identify these modes in experiments according to their frequencies without considering their polarized configurations.

IR and Raman intensities of $\mathrm{Bi}_{2} \mathrm{O}_{2} \mathrm{Se}$ and $\mathrm{Bi}_{2} \mathrm{O}_{2}$ Te are also calculated directly by first principles calculations based on the
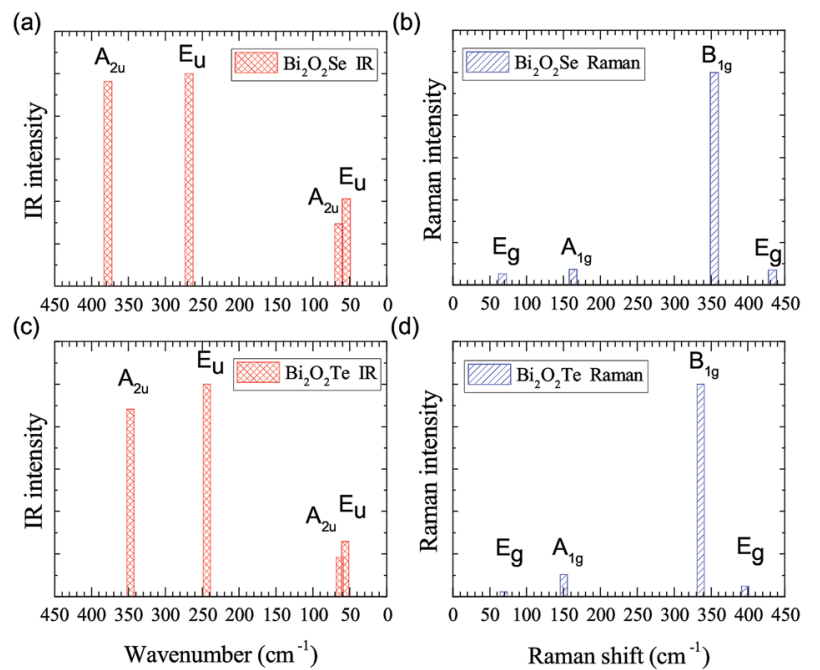

Fig. 3 Calculated IR and Raman intensities (arbitrary unit) of $\mathrm{Bi}_{2} \mathrm{O}_{2} \mathrm{Se}$ and $\mathrm{Bi}_{2} \mathrm{O}_{2} \mathrm{Te}$. 
Table 4 Comparison between calculated and experimental Raman frequencies of $\mathrm{Bi}_{2} \mathrm{O}_{2} \mathrm{Se}$

Raman frequency $\left(\mathrm{cm}^{-1}\right)$

This work Experiment $^{14}$

Experiment $^{16}$

Experiment $^{37}$

Experiment $^{38}$

$67.3\left(\mathrm{E}_{\mathrm{g}}\right), 162.9\left(\mathrm{~A}_{1 \mathrm{~g}}\right), 354.3\left(\mathrm{~B}_{1 \mathrm{~g}}\right), 433.3\left(\mathrm{E}_{\mathrm{g}}\right)$

100,159

84/90 ( $\left.E_{g}^{2}\right), 159\left(A_{1 g}\right)$

$159.2\left(\mathrm{~A}_{1 \mathrm{~g}}\right)$

$160\left(\mathrm{~A}_{1 \mathrm{~g}}\right)$

equations in Section II, which are shown in Fig. 3. From Fig. 3(a) and (c), we can see that the two high-frequency IR active modes $\left(\mathrm{E}_{\mathrm{u}}\right.$ and $\left.\mathrm{A}_{2 \mathrm{u}}\right)$ have relatively higher intensities than those of the low-frequency modes $\left(\mathrm{E}_{\mathrm{u}}\right.$ and $\left.\mathrm{A}_{2 \mathrm{u}}\right)$. On the other hand, in Fig. 3(b) and (d), the Raman active mode $\mathrm{B}_{1 \mathrm{~g}}$ has the highest intensity for both materials, while the other three modes have much lower intensities.

Recently, there have been four experimental works, ${ }^{14,16,37,38}$ in which the Raman spectrum of $\mathrm{Bi}_{2} \mathrm{O}_{2}$ Se was given. Wu et al. have synthesized the atomically thin two-dimensional and the bulk $\mathrm{Bi}_{2} \mathrm{O}_{2}$ Se crystals and they observed two Raman peaks located at about 100 and $159 \mathrm{~cm}^{-1} \cdot{ }^{\mathbf{1 4}}$ Tong et al. have grown high-quality $\mathrm{Bi}_{2} \mathrm{O}_{2} \mathrm{Se}$ single crystals and found two main Raman peaks located at around 90 and $159 \mathrm{~cm}^{-1}$, which are associated with the symmetries of $\mathrm{E}_{\mathrm{g}}^{2}$ and $\mathrm{A}_{1 \mathrm{~g}}^{2}$ respectively. ${ }^{16}$ However, it seems that the $\mathrm{E}_{\mathrm{g}}^{2}$ mode in their Figure is made up of two adjacent peaks located at 84 and $90 \mathrm{~cm}^{-1} \cdot{ }^{16}$ Pereira et al. studied the physical properties of $\mathrm{Bi}_{2} \mathrm{O}_{2} \mathrm{Se}$ at high pressure, in which they only observed one most intense Raman peak at around $159.2 \mathrm{~cm}^{-1}$ at room pressure. ${ }^{37}$ The theoretical low-frequency $\mathrm{E}_{\mathrm{g}}$ mode (near $70 \mathrm{~cm}^{-1}$ ) can only be observed at high pressure. ${ }^{37}$ Cheng et al. have measured the Raman spectra of $\mathrm{Bi}_{2} \mathrm{O}_{2} \mathrm{Se}$ and $\mathrm{Bi}_{2} \mathrm{O}_{2} \mathrm{Te}^{38}$ These results are summarized in Table 4 , from which we can see that the Raman active mode $\mathrm{A}_{1 \mathrm{~g}}$ at about $160 \mathrm{~cm}^{-1}$ can be well confirmed, while the $\mathrm{E}_{\mathrm{g}}$ mode below $100 \mathrm{~cm}^{-1}$ is ambiguous. The discrepancy of the low-frequency $E_{g}$ modes in the two experiments ${ }^{\mathbf{1 4 , 1 6}}$ is more than $10 \mathrm{~cm}^{-1}$, and meanwhile both observed frequencies of the $\mathrm{E}_{\mathrm{g}}$ modes are about 20$30 \mathrm{~cm}^{-1}$ higher than the theoretical result. Furthermore, the two high-frequency Raman active modes $\left(B_{1 g}\right.$ and $\left.E_{g}\right)$ have not been observed in all the experiments ${ }^{14,16,37,38}$ in spite of the high intensity of the $\mathrm{B}_{1 \mathrm{~g}}$ mode in our calculations. The possible reason is due to the phonon damping caused by the large carrier concentration in $\mathrm{Bi}_{2} \mathrm{O}_{2} \mathrm{Se}$, as indicated in Pereira's work. ${ }^{37}$

The Raman spectrum of $\mathrm{Bi}_{2} \mathrm{O}_{2}$ Te was also measured in Cheng's work, ${ }^{38}$ which is listed in Table 5 . The two observed Raman modes $\left(\mathrm{A}_{1 \mathrm{~g}}\right.$ and $\left.\mathrm{B}_{1 \mathrm{~g}}\right)$ are well consistent with our calculations. However, the two $\mathrm{E}_{\mathrm{g}}$ modes are not observed in

Table 5 Comparison between calculated and experimental Raman frequencies of $\mathrm{Bi}_{2} \mathrm{O}_{2} \mathrm{Te}$

Raman frequency $\left(\mathrm{cm}^{-1}\right)$

This work

Experiment $^{38}$

$69.1\left(\mathrm{E}_{\mathrm{g}}\right), 147.48\left(\mathrm{~A}_{1 \mathrm{~g}}\right), 336.0\left(\mathrm{~B}_{1 \mathrm{~g}}\right), 396.1\left(\mathrm{E}_{\mathrm{g}}\right)$ $147\left(\mathrm{~A}_{1 \mathrm{~g}}\right), 340\left(\mathrm{~B}_{1 \mathrm{~g}}\right)$ their work. It is interesting to point out that the missing $\mathrm{B}_{1 \mathrm{~g}}$ mode in $\mathrm{Bi}_{2} \mathrm{O}_{2}$ Se was observed in $\mathrm{Bi}_{2} \mathrm{O}_{2}$ Te, although in a relatively low intensity compared to that of the $\mathrm{A}_{1 \mathrm{~g}}$ mode. Therefore, the Raman spectra of $\mathrm{Bi}_{2} \mathrm{O}_{2} \mathrm{Se}$ and $\mathrm{Bi}_{2} \mathrm{O}_{2}$ Te need further investigations. For example, one could try to measure the Raman spectrum of $\mathrm{Bi}_{2} \mathrm{O}_{2} \mathrm{Se}$ with a lower carrier concentration by doping or at low temperatures in a proper Raman polarized configuration.

\subsection{Pnnm orthorhombic $\mathrm{Bi}_{2} \mathrm{O}_{2} \mathrm{~S}$}

Although $\mathrm{Bi}_{2} \mathrm{O}_{2} \mathrm{~S}$ has a very similar crystal structure to the one of $\mathrm{Bi}_{2} \mathrm{O}_{2} \mathrm{Se}$ shown in Fig. 1(a) and (b), they have a different symmetry. In fact, $\mathrm{Bi}_{2} \mathrm{O}_{2} \mathrm{~S}$ has an orthorhombic crystal structure with a space group of Pnnm (point group $D_{2 \mathrm{~h}}$ ). There are ten atoms in the unit cell of $\mathrm{Bi}_{2} \mathrm{O}_{2} \mathrm{~S}$ resulting in thirty phonon modes. Its irreducible representations at the $\Gamma$ point are presented as follows:

$$
\begin{gathered}
\Gamma_{\text {acoustic }}=\mathrm{B}_{1 \mathrm{u}}+\mathrm{B}_{2 \mathrm{u}}+\mathrm{B}_{3 \mathrm{u}} \\
\Gamma_{\text {optic }}=3 \mathrm{~A}_{\mathrm{u}}+2 \mathrm{~B}_{1 \mathrm{u}}+5 \mathrm{~B}_{2 \mathrm{u}}+5 \mathrm{~B}_{3 \mathrm{u}}+4 \mathrm{~A}_{\mathrm{g}}+4 \mathrm{~B}_{1 \mathrm{~g}}+2 \mathrm{~B}_{2 \mathrm{~g}}+2 \mathrm{~B}_{3 \mathrm{~g}}
\end{gathered}
$$

The calculated zone-centered optical phonon frequencies of $\mathrm{Bi}_{2} \mathrm{O}_{2} \mathrm{~S}$ and their symmetries are listed in Table 6. It is found that all of the modes are non-degenerate. According to the character table of the $D_{2 \mathrm{~h}}$ point group, the $\mathrm{B}_{1 \mathrm{u}}, \mathrm{B}_{2 \mathrm{u}}$, and $\mathrm{B}_{3 \mathrm{u}}$ modes are IR active, while the $A_{g}, B_{1 g}, B_{2 g}$ and $B_{3 g}$ modes are Raman active. The $A_{u}$ modes are neither IR nor Raman active. From our calculation, $\mathrm{Bi}_{2} \mathrm{O}_{2} \mathrm{~S}$ should have twelve Raman and twelve IR active modes, as shown in Table 6.

The vibrational eigenvectors of all the zone-centered optical modes and the polarized configurations of the Raman active modes are shown in Fig. S1 and Tables S1 and S2 in the ESI. $\dagger$

IR and Raman intensities of $\mathrm{Bi}_{2} \mathrm{O}_{2} \mathrm{~S}$ are also calculated directly by first principles calculations, which are shown in Fig. 4. It is found that the IR modes near 60,290 and $400 \mathrm{~cm}^{-1}$ have the highest intensities. In the Raman spectrum, the three

Table 6 Mulliken symbols and frequencies of zone-centered optical phonon modes of $\mathrm{Bi}_{2} \mathrm{O}_{2} \mathrm{~S}$. Raman or IR activity of each mode is also indicated by "Raman" and "IR". The $A_{u}$ mode is neither Raman nor IR active. The unit of the phonon frequency is $\mathrm{cm}^{-1}$

\begin{tabular}{lrllll}
\hline Symmetry & $\mathrm{Bi}_{2} \mathrm{O}_{2} \mathrm{~S}$ & Activity & Symmetry & $\mathrm{Bi}_{2} \mathrm{O}_{2} \mathrm{~S}$ & Activity \\
\hline $\mathrm{B}_{2 \mathrm{~g}}$ & 9.5 & Raman & $\mathrm{B}_{3 \mathrm{u}}$ & 218.8 & IR \\
$\mathrm{A}_{\mathrm{g}}$ & 13.9 & Raman & $\mathrm{A}_{\mathrm{g}}$ & 285.2 & Raman \\
$\mathrm{A}_{\mathrm{u}}$ & 53.7 & & $\mathrm{~B}_{3 \mathrm{u}}$ & 286.3 & IR \\
$\mathrm{B}_{2 \mathrm{u}}$ & 54.9 & $\mathrm{IR}$ & $\mathrm{B}_{2 \mathrm{~g}}$ & 287.7 & Raman \\
$\mathrm{B}_{3 \mathrm{u}}$ & 60.7 & $\mathrm{IR}$ & $\mathrm{B}_{1 \mathrm{u}}$ & 288.5 & IR \\
$\mathrm{B}_{1 \mathrm{u}}$ & 64.9 & $\mathrm{IR}$ & $\mathrm{B}_{3 \mathrm{u}}$ & 364.4 & IR \\
$\mathrm{B}_{3 \mathrm{~g}}$ & 65.2 & Raman & $\mathrm{A}_{\mathrm{g}}$ & 367.8 & Raman \\
$\mathrm{B}_{1 \mathrm{~g}}$ & 67.9 & Raman & $\mathrm{B}_{2 \mathrm{u}}$ & 404.2 & IR \\
$\mathrm{B}_{2 \mathrm{u}}$ & 75.7 & $\mathrm{IR}$ & $\mathrm{A}_{\mathrm{u}}$ & 448.9 & \\
$\mathrm{~B}_{1 \mathrm{~g}}$ & 83.0 & Raman & $\mathrm{B}_{1 \mathrm{~g}}$ & 450.6 & Raman \\
$\mathrm{A}_{\mathrm{u}}$ & 113.1 & & $\mathrm{~B}_{3 \mathrm{~g}}$ & 452.4 & Raman \\
$\mathrm{B}_{2 \mathrm{u}}$ & 113.4 & $\mathrm{IR}$ & $\mathrm{B}_{2 \mathrm{u}}$ & 457.5 & IR \\
$\mathrm{B}_{3 \mathrm{u}}$ & 144.7 & $\mathrm{IR}$ & $\mathrm{B}_{1 \mathrm{~g}}$ & 519.1 & Raman \\
$\mathrm{A}_{\mathrm{g}}$ & 170.6 & Raman & & &
\end{tabular}


(a)

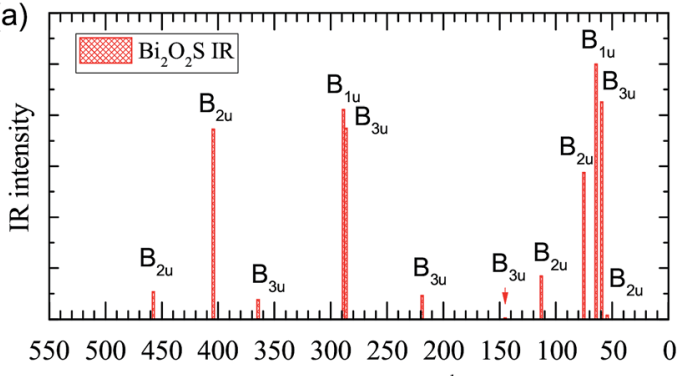

Wavenumber $\left(\mathrm{cm}^{-1}\right)$

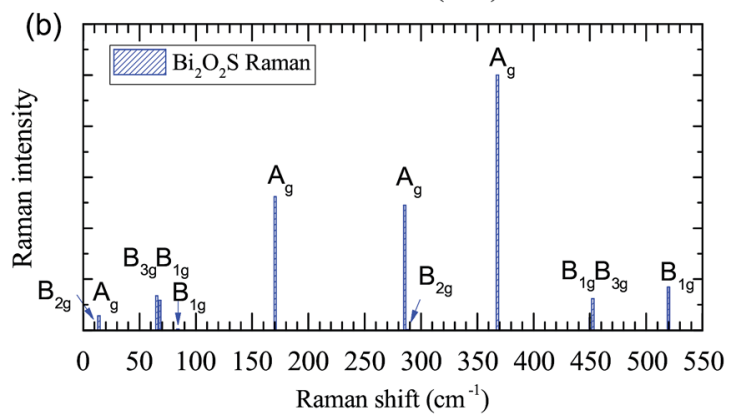

Fig. 4 Calculated IR and Raman intensities (arbitrary unit) of orthorhombic $\mathrm{Bi}_{2} \mathrm{O}_{2} \mathrm{~S}$.

$\mathrm{A}_{\mathrm{g}}$ modes near 170,285 , and $370 \mathrm{~cm}^{-1}$ have the highest intensities.

It is noted that $\mathrm{Bi}_{2} \mathrm{O}_{2} \mathrm{~S}$ has been synthesized in experiments, ${ }^{24-26}$ however no Raman spectrum was measured yet. Recently, Cheng et al. have also calculated the Raman spectrum of $\mathrm{Bi}_{2} \mathrm{O}_{2} \mathrm{~S}$ by the density functional perturbation theory in the local density approximation and norm-conserving pseudopotentials implemented in Quantum Espresso (QE) software. ${ }^{38} \mathrm{We}$ listed their data in Table 7 as well as ours for comparison. From the frequency perspective, we can see that the two calculations are in general consistent with each other. For example, in both works, there are five Raman modes below $100 \mathrm{~cm}^{-1}$, one mode between $100-200 \mathrm{~cm}^{-1}$, two modes between $200-300 \mathrm{~cm}^{-1}$, and etc. Although the largest difference in a $\mathrm{B}_{1 \mathrm{~g}}$ mode reaches $43 \mathrm{~cm}^{-1}$ (about 10\%), we still think it is acceptable since the two works use totally different methods in their calculations.

However, we noted that the Mulliken symbols in the two works are quite different. In particular, the four $\mathrm{A}_{\mathrm{g}}$ modes in Cheng's work are all below $200 \mathrm{~cm}^{-1}$, while we have two $A_{g}$ modes below $200 \mathrm{~cm}^{-1}$ and two other ones above $200 \mathrm{~cm}^{-1}$. The highest $\mathrm{A}_{\mathrm{g}}$ mode in our work is more than $210 \mathrm{~cm}^{-1}$ higher than theirs. This cannot be explained by the inaccuracy of the phonon frequency induced by the different parameters. It is possibly due to the different classification of the Mulliken symbols. In the $D_{2 \mathrm{~h}}$ point group, the assignment of $\mathrm{B}_{1 \mathrm{~g}}, \mathrm{~B}_{2 \mathrm{~g}}$, and $B_{3 g}$ depends on the three mutually perpendicular 2-fold axes along the $z, y$, and $x$ directions. ${ }^{56}$ We have tested that $\mathrm{QE}$ software will give different Mulliken symbols $\left(\mathrm{B}_{1 \mathrm{~g}}, \mathrm{~B}_{2 \mathrm{~g}}\right.$, and $\left.\mathrm{B}_{3 \mathrm{~g}}\right)$ depending on the orientations of the orthorhombic unit cell of $\mathrm{Bi}_{2} \mathrm{O}_{2} \mathrm{~S}$. However, the assignment of the $\mathrm{A}_{\mathrm{g}}$ mode should be unambiguous, which is independent of the directions of the unit cell. Therefore, we think the discrepancy of the $A_{g}$ Raman modes in our work and Cheng's work needs further investigations.

\section{$3.4 P 4 /$ nmm tetragonal $\mathrm{Bi}_{2} \mathrm{OS}_{2}, \mathrm{Bi}_{2} \mathrm{OSe}_{2}$, and $\mathrm{Bi}_{2} \mathrm{OTe}_{2}$}

In experiment, $\mathrm{Bi}_{2} \mathrm{OS}_{2}$ has a space group of $\mathrm{P} 4 / \mathrm{mmm}$ (point group $\left.D_{4 \mathrm{~h}}\right)^{28,55}$ However, to the best of our knowledge, $\mathrm{Bi}_{2} \mathrm{OSe}_{2}$ and $\mathrm{Bi}_{2} \mathrm{OTe}_{2}$ have not been synthesized in experiment. First principles calculations indicate that they share the same crystal structure as $\mathrm{Bi}_{2} \mathrm{OS}_{2} \cdot{ }^{30}$ There are ten atoms in the unit cell of $\mathrm{Bi}_{2} \mathrm{OX}_{2}(\mathrm{X}=\mathrm{S}$, Se, and Te) as shown in Fig. 1(c), resulting in thirty phonon modes. The irreducible representations of $\mathrm{Bi}_{2} \mathrm{OX}_{2}$ at the $\Gamma$ point are:

$$
\begin{gathered}
\Gamma_{\text {acoustic }}=\mathrm{E}_{\mathrm{u}}+\mathrm{A}_{2 \mathrm{u}} \\
\Gamma_{\text {optic }}=4 \mathrm{E}_{\mathrm{u}}+4 \mathrm{~A}_{2 \mathrm{u}}+5 \mathrm{E}_{\mathrm{g}}+4 \mathrm{~A}_{1 \mathrm{~g}}+\mathrm{B}_{1 \mathrm{~g}}
\end{gathered}
$$

The zone-centered optical phonon frequencies and their symmetries of $\mathrm{Bi}_{2} \mathrm{OX}_{2}$ are listed in Table 8. The vibrational eigenvectors of $\mathrm{Bi}_{2} \mathrm{OS}_{2}$ are shown in Fig. $\mathrm{S} 2$ in the ESI. $\uparrow$ The polarized configurations of the Raman spectra of $\mathrm{Bi}_{2} \mathrm{OX}_{2}$ should be the same as those of $\mathrm{Bi}_{2} \mathrm{O}_{2} \mathrm{Se}$ (Table 3) since they all belong to the $D_{4 \mathrm{~h}}$ point group.

According to the character table for the $D_{4 \mathrm{~h}}$ point group, the $\mathrm{E}_{\mathrm{u}}$ and $\mathrm{A}_{2 \mathrm{u}}$ modes are IR active, while the $\mathrm{E}_{\mathrm{g}}, \mathrm{A}_{1 \mathrm{~g}}$, and $\mathrm{B}_{1 \mathrm{~g}}$ modes are Raman active. Therefore, there are ten Raman active (five double degenerated $\mathrm{E}_{\mathrm{g}}$ modes, five non-degenerated $\mathrm{A}_{1 \mathrm{~g}}$ and $\mathrm{B}_{1 \mathrm{~g}}$ modes) and eight IR active modes (four double degenerated $\mathrm{E}_{\mathrm{u}}$ modes and four non-degenerated $\mathrm{A}_{2 \mathrm{u}}$ ones) in $\mathrm{Bi}_{2} \mathrm{OX}_{2}$.

The IR and Raman intensities of $\mathrm{Bi}_{2} \mathrm{OX}_{2}$ are also calculated directly by first principles calculations, which are shown in Fig. 5. It is found that in the IR spectrum of $\mathrm{Bi}_{2} \mathrm{OS}_{2}$, there are six modes $\left(E_{\mathrm{u}}\right.$ modes around $98,127,262 \mathrm{~cm}^{-1}$ and $A_{2 u}$ modes around 129, 286, $466 \mathrm{~cm}^{-1}$ ) which have relatively high intensities. For the $\mathrm{Bi}_{2} \mathrm{OSe}_{2}$ and $\mathrm{Bi}_{2} \mathrm{OTe}_{2}$, only four modes have high intensities. For the Raman spectra of $\mathrm{Bi}_{2} \mathrm{OS}_{2}$ and $\mathrm{Bi}_{2} \mathrm{OSe}_{2}$, there are two promising $\mathrm{A}_{1 \mathrm{~g}}$ peaks around 132 and $346 \mathrm{~cm}^{-1}$ for $\mathrm{Bi}_{2} \mathrm{OS}_{2}$, and 89 and $218 \mathrm{~cm}^{-1}$ for $\mathrm{Bi}_{2} \mathrm{OSe}_{2}$. For $\mathrm{Bi}_{2} \mathrm{OTe}_{2}$, the $\mathrm{A}_{1 \mathrm{~g}}$ Raman mode around $163 \mathrm{~cm}^{-1}$ has the highest intensity.

Table 7 Comparison between the theoretical Raman frequencies of $\mathrm{Bi}_{2} \mathrm{O}_{2} \mathrm{~S}$. For each row, the Raman modes are arranged according to their

\begin{tabular}{|c|c|c|c|c|c|c|c|c|c|c|c|c|}
\hline This work & $\begin{array}{l}B_{2 g} \\
9.5\end{array}$ & $\begin{array}{l}\mathrm{A}_{\mathrm{g}} \\
13.9\end{array}$ & $\begin{array}{l}B_{3 g} \\
65.2\end{array}$ & $\begin{array}{l}\mathrm{B}_{1 \mathrm{~g}} \\
67.9\end{array}$ & $\begin{array}{l}\mathrm{B}_{1 \mathrm{~g}} \\
83.0\end{array}$ & $\begin{array}{l}\mathrm{A}_{\mathrm{g}} \\
170.6\end{array}$ & $\begin{array}{l}\mathrm{A}_{\mathrm{g}} \\
285.2\end{array}$ & $\begin{array}{l}B_{2 g} \\
287.7\end{array}$ & $\begin{array}{l}\mathrm{A}_{\mathrm{g}} \\
367.8\end{array}$ & $\begin{array}{l}\mathrm{B}_{1 \mathrm{~g}} \\
450.6\end{array}$ & $\begin{array}{l}\mathrm{B}_{3 \mathrm{~g}} \\
452.4\end{array}$ & $\begin{array}{l}\mathrm{B}_{1 \mathrm{~g}} \\
519.1\end{array}$ \\
\hline
\end{tabular}
frequencies. The unit of the phonon frequency is $\mathrm{cm}^{-1}$ 
Table 8 Mulliken symbols and frequencies of zone-centered optical phonon modes of $\mathrm{Bi}_{2} \mathrm{OX}_{2}(X=S$, Se and Te). Raman or IR activity of each mode is also indicated by "Raman" and "IR". The unit of the phonon frequency is $\mathrm{cm}^{-1}$

\begin{tabular}{lcccl}
\hline Symmetry & $\mathrm{Bi}_{2} \mathrm{OS}_{2}$ & $\mathrm{Bi}_{2} \mathrm{OSe}_{2}$ & $\mathrm{Bi}_{2} \mathrm{OTe}_{2}$ & Activity \\
\hline $\mathrm{E}_{\mathrm{u}}$ & 26.0 & 18.8 & 6.5 & IR \\
$\mathrm{E}_{\mathrm{g}}$ & 30.7 & 25.9 & 20.0 & Raman \\
$\mathrm{E}_{\mathrm{g}}$ & 63.2 & 55.8 & 41.1 & Raman \\
$\mathrm{A}_{2 \mathrm{u}}$ & 63.9 & 54.6 & 50.6 & IR \\
$\mathrm{A}_{1 \mathrm{~g}}$ & 73.2 & 64.1 & 53.5 & Raman \\
$\mathrm{E}_{\mathrm{u}}$ & 97.7 & 73.2 & 49.2 & IR \\
$\mathrm{E}_{\mathrm{g}}$ & 111.4 & 80.5 & 54.8 & Raman \\
$\mathrm{E}_{\mathrm{u}}$ & 126.6 & 89.4 & 83.5 & IR \\
$\mathrm{A}_{2 \mathrm{u}}$ & 129.4 & 97.2 & 84.5 & IR \\
$\mathrm{A}_{1 \mathrm{~g}}$ & 132.2 & 88.6 & 75.1 & Raman \\
$\mathrm{E}_{\mathrm{g}}$ & 138.4 & 100.2 & 101.1 & Raman \\
$\mathrm{A}_{1 \mathrm{~g}}$ & 149.7 & 138.6 & 123.9 & Raman \\
$\mathrm{E}_{\mathrm{u}}$ & 262.1 & 228.1 & 183.7 & IR \\
$\mathrm{A}_{2 \mathrm{u}}$ & 286.0 & 182.3 & 140.9 & IR \\
$\mathrm{A}_{1 \mathrm{~g}}$ & 346.5 & 217.9 & 163.2 & Raman \\
$\mathrm{B}_{1 \mathrm{~g}}$ & 363.5 & 342.2 & 311.2 & Raman \\
$\mathrm{E}_{\mathrm{g}}$ & 415.0 & 376.0 & 321.9 & Raman \\
$\mathrm{A}_{2 \mathrm{u}}$ & 466.0 & 420.0 & 372.1 & IR \\
\hline
\end{tabular}

Since the tetragonal $\mathrm{Bi}_{2} \mathrm{OSe}_{2}$ and $\mathrm{Bi}_{2} \mathrm{OTe}_{2}$ have not been synthesized in experiments, we also calculated their phonon dispersion and densities of state, which are not shown here. No imaginary frequencies are found in both materials. Therefore we think the tetragonal phases of $\mathrm{Bi}_{2} \mathrm{OSe}_{2}$ and $\mathrm{Bi}_{2} \mathrm{OTe}_{2}$ are stable and they could possibly be synthesized in future experiments.
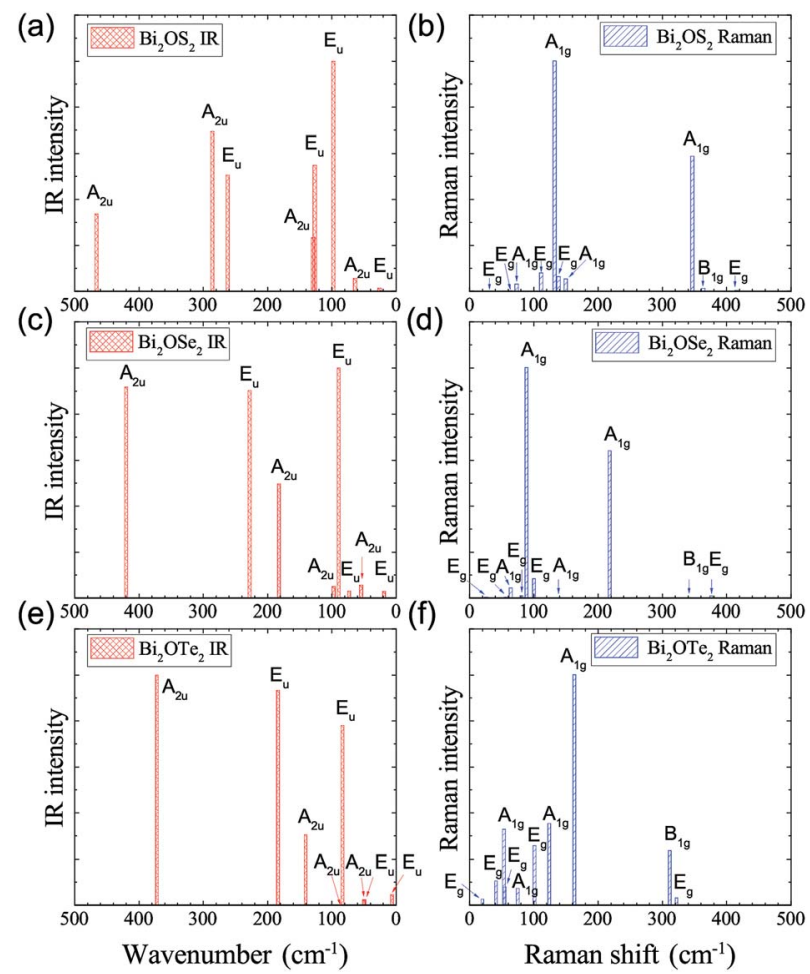

Fig. 5 Calculated IR and Raman intensities (arbitrary unit) of tetragonal $\mathrm{Bi}_{2} \mathrm{OX}_{2}(\mathrm{X}=\mathrm{S}$, Se, and Te).

\section{Conclusions}

We have systematically calculated the Raman and infrared spectra of six Bi-O-X materials: $\mathrm{Bi}_{2} \mathrm{O}_{2} \mathrm{X}$ and $\mathrm{Bi}_{2} \mathrm{OX}_{2}(\mathrm{X}=\mathrm{S}$, Se, and $\mathrm{Te}$ ). For each material, we present their optical phonon frequencies, Raman and infrared activities and intensities, Raman polarization configurations, and vibrational eigenvectors. In particular, the Raman spectra of $\mathrm{Bi}_{2} \mathrm{O}_{2} \mathrm{Se}$ and $\mathrm{Bi}_{2} \mathrm{O}_{2} \mathrm{Te}$ are compared with the existing experimental results. In $\mathrm{Bi}_{2} \mathrm{O}_{2} \mathrm{Se}$, only one $\mathrm{A}_{1 \mathrm{~g}}$ Raman mode is confirmed in experiments, while the other three are ambiguous or not observed yet. In $\mathrm{Bi}_{2} \mathrm{O}_{2} \mathrm{Te}$, both $\mathrm{A}_{1 \mathrm{~g}}$ and $\mathrm{B}_{1 \mathrm{~g}}$ modes are well consistent with the experiments, while two $\mathrm{E}_{\mathrm{g}}$ modes are not observed yet. Due to the various and important physical properties in these materials, our work could be helpful in identifying the crystal structure in future experiments.

\section{Conflicts of interest}

There are no conflicts to declare.

\section{Acknowledgements}

This work is supported by the National Key R\&D Program of China (Grant No. 2016YFA0201104), National Basic Research Program of China (Grant No. 2015CB659400), National Natural Science Foundation of China (Grant No. 51872134, No. 51890860, No. 11890702, and No. 51721001), and the Natural Science Foundation of Jiangsu Province, China (Grant No. BK20171343). Y. Y. Lv acknowledges the financial support from the Innovation Program for the Talents of China Postdoctoral Science Foundation (BX20180137). The use of the computational resources in the High Performance Computing Center of Nanjing University for this work is also acknowledged.

\section{References}

1 H. Boller, Monatsh. Chem., 1973, 104, 916.

2 P. Ruleova, C. Drasar, P. Lostak, C. P. Li, S. Ballikaya and C. Uher, Mater. Chem. Phys., 2010, 119, 299.

3 K. Y. Zhang, C. G. Hu, Z. L. Kang, S. X. Wang, Y. Xi and H. Liu, Mater. Res. Bull., 2013, 48, 3968.

4 B. Zhan, Y. C. Liu, J. L. Lan, C. C. Zeng, Y. H. Lin and C. W. Nan, Materials, 2015, 8, 1568.

5 X. Tan, J. L. Lan, Y. C. Liu, G. K. Ren, C. C. Zeng, Y. H. Lin and C. W. Nan, J. Electroceram., 2016, 37, 66.

6 R. Liu, J. L. Lan, X. Tan, Y. C. Liu, G. K. Ren, C. Liu, Z. F. Zhou, C. W. Nan and Y. H. Lin, J. Eur. Ceram. Soc., 2018, 38, 2742.

7 X. Tan, J. L. Lan, K. R. Hu, B. Xu, Y. C. Liu, P. Zhang, X. Z. Cao, Y. C. Zhu, W. Xu, Y. H. Lin and C. W. Nan, J. Am. Ceram. Soc., 2018, 101, 4634.

8 D. L. Guo, C. G. Hu, Y. Xi and K. Zhang, J. Phys. Chem. C, 2013, 117, 21597.

9 T. V. Quang and M. Kim, J. Appl. Phys., 2016, 120, 195105. 10 M. Liangruksa, Mater. Res. Express, 2017, 4, 035703. 
11 C. Wang, G. Q. Ding, X. M. Wu, S. S. Wei and G. Y. Gao, New J. Phys., 2018, 20, 123014.

12 C. Drasar, P. Ruleova, L. Benes and P. Lostak, J. Electron. Mater., 2012, 41, 2317.

13 J. X. Wu, H. T. Yuan, M. M. Meng, C. Chen, Y. Sun, Z. Y. Chen, W. H. Dang, C. W. Tan, Y. J. Liu, J. B. Yin, Y. B. Zhou, S. Y. Huang, H. Q. Xu, Y. Cui, H. Y. Hwang, Z. F. Liu, Y. L. Chen, B. H. Yan and H. L. Peng, Nat. Nanotechnol., 2017, 12, 530.

14 J. X. Wu, C. W. Tan, Z. J. Tan, Y. J. Liu, J. B. Yin, W. H. Dang, M. Z. Wang and H. L. Peng, Nano Lett., 2017, 17, 3021.

15 C. Chen, M. X. Wang, J. X. Wu, H. X. Fu, H. F. Yang, Z. Tian, T. Tu, H. Peng, Y. Sun, X. Xu, J. Jiang, N. B. M. Schröter, Y. W. Li, D. Pei, S. Liu, S. A. Ekahana, H. T. Yuan, J. M. Xue, G. Li, J. F. Jia, Z. K. Liu, B. H. Yan, H. L. Peng and Y. L. Chen, $S c i$. Adv., 2018, 4, eaat8355.

16 T. Tong, M. Zhang, Y. Chen, Y. Li, L. Chen, J. Zhang, F. Song, X. Wang, W. Zou, Y. Xu and R. Zhang, Appl. Phys.Lett., 2018, 113, 072106.

17 Y. Y. Lv, L. Xu, S. T. Dong, Y. C. Luo, Y. Y. Zhang, Y. B. Chen, S. H. Yao, J. Zhou, Y. S. Cui, S. T. Zhang, M. H. Lu and Y. F. Chen, Phys. Rev. B, 2019, 99, 195143.

18 H. X. Fu, J. X. Wu, H. L. Peng and B. H. Yan, Phys. Rev. B, 2018, 97, 241203.

19 Y. Y. Lv, X. Li, J. L. Zhang, B. Pang, S. S. Chen, L. Cao, B. B. Zhang, D. J. Lin, Y. B. Chen, S. H. Yao, J. Zhou, S. T. Zhang, M. H. Lu, M. L. Tian and Y. F. Chen, Phys. Rev. B, 2018, 97, 245151.

20 J. Li, Z. X. Wang, Y. Wen, J. W. Chu, L. Yin, R. Q. Cheng, L. Lei, P. He, C. Jiang, L. P. Feng and J. He, Adv. Funct. Mater., 2018, 28, 1706437.

21 J. X. Wu, Y. J. Liu, Z. J. Tan, C. W. Tan, J. B. Yin, T. R. Li, T. Tu and H. L. Peng, Adv. Mater., 2017, 29, 1704060.

22 J. Yin, Z. Tan, H. Hong, J. Wu, H. Yuan, Y. Liu, C. Chen, C. Tan, F. Yao, T. Li, Y. Chen, Z. Liu, K. Liu and H. Peng, Nat. Commun., 2018, 9, 3311.

23 S. D. N. Luu and P. Vaqueiro, J. Solid State Chem., 2015, 226, 219.

24 E. Koyama, I. Nakai and K. Nagashima, Acta Crystallogr., Sect. B: Struct. Sci., 1984, 40, 105.

25 A. L. Pacquette, H. Hagiwara, T. Ishihara and A. A. Gewirth, J. Photochem. Photobiol., A, 2014, 277, 27.

26 I. A. Kariper, Spectrochim. Acta, Part A, 2016, 163, 102.

27 X. Zhang, Y. Liu, G. Zhang, Y. Wang, H. Zhang and F. Huang, ACS Appl. Mater. Interfaces, 2015, 7, 4442.

28 A. Miura, Y. Mizuguchi, T. Takei, N. Kumada, E. Magome, C. Moriyoshi, Y. Kuroiwa and K. Tadanaga, Solid State Commun., 2016, 227, 19.

29 X. W. Zhang, B. Wang, X. H. Niu, Y. H. Li, Y. F. Chen and J. L. Wang, Mater. Horiz., 2018, 5, 1058.

30 X. Ma, D. Chang, C. Zhao, R. Li, X. Huang, Z. Zeng, X. Huang and Y. Jia, J. Mater. Chem. C, 2018, 6, 13241.
31 S. Azam, S. A. Khan and S. Goumri-Said, J. Electron. Mater., 2018, 47, 2513.

32 S. K. Singh, A. Kumar, B. Gahtori, S. G. Sharma, S. Patnaik and V. P. S. Awana, J. Am. Chem. Soc., 2012, 134, 16504.

33 Y. Mizuguchi, H. Fujihisa, Y. Gotoh, K. Suzuki, H. Usui, K. Kuroki, S. Demura, Y. Takano, H. Izawa and O. Miura, Phys. Rev. B: Condens. Matter Mater. Phys., 2012, 86, 220510(R).

34 W. A. Phelan, D. C. Wallace, K. E. Arpino, J. R. Neilson, K. J. Livi, C. R. Seabourne, A. J. Scott and T. M. McQueen, J. Am. Chem. Soc., 2013, 135, 5372.

35 L. Li, D. Parker, P. Babkevich, L. Yang, H. M. Ronnow and A. S. Sefat, Phys. Rev. B: Condens. Matter Mater. Phys., 2015, 91, 104511.

36 J. F. Shao, Z. H. Liu, X. Yao, L. Pi, S. Tan, C. J. Zhang and Y. H. Zhang, Phys. Status Solidi RRL, 2014, 8, 845.

37 A. L. J. Pereira, D. Santamaría-Pérez, J. Ruiz-Fuertes, F. J. Manjón, V. P. Cuenca-Gotor, R. Vilaplana, O. Gomis, C. Popescu, A. Muñoz, P. Rodríguez-Hernández, A. Segura, L. Gracia, A. Beltraán, P. Ruleova, C. Drasar and J. A. Sans, J. Phys. Chem. C, 2018, 122, 8853.

38 T. Cheng, C. W. Tan, S. Q. Zhang, T. Tu, H. L. Peng and Z. R. Liu, J. Phys. Chem. C, 2018, 122, 19970.

39 G. Kresse and J. Furthmüller, Comput. Mater. Sci., 1996, 6, 15. 40 G. Kresse and J. Furthmüller, Phys. Rev. B: Condens. Matter Mater. Phys., 1996, 54, 11169.

41 P. E. Blöchl, Phys. Rev. B: Condens. Matter Mater. Phys., 1994, 50, 17953.

42 G. Kresse and D. Joubert, Phys. Rev. B: Condens. Matter Mater. Phys., 1999, 59, 1758.

43 J. P. Perdew, K. Burke and M. Ernzerhof, Phys. Rev. Lett., 1996, 77, 3865.

44 S. Grimme, J. Antony, S. Ehrlich and H. Krieg, J. Chem. Phys., 2010, 132, 154104.

45 S. Grimme, S. Ehrlich and L. Goerigk, J. Comput. Chem., 2011, 32, 1456.

46 A. Togo and I. Tanaka, Scr. Mater., 2015, 108, 1.

47 K. Momma and F. Izumi, J. Appl. Crystallogr., 2011, 44, 1272. 48 P. Giannozzi and S. Baroni, J. Chem. Phys., 1994, 100, 8537. 49 J. Zhou and J. Dong, J. Appl. Phys., 2010, 107, 024306.

50 D. Karhánek, T. Bučko and J. Hafner, J. Phys.: Condens. Matter, 2010, 22, 265006.

51 K. Esfarjani, Y. Hashi, J. Onoe, K. Takeuchi and Y. Kawazoe, Phys. Rev. B: Condens. Matter Mater. Phys., 1998, 57, 223.

52 A. Fonari and S. Stauffer, vasp_raman.py, https:// github.com/raman-sc/VASP/.

53 J. M. Skelton, L. A. Burton, A. J. Jackson, F. Oba, S. C. Parker and A. Walsh, Phys. Chem. Chem. Phys., 2017, 19, 12452.

54 D. T. Larson and E. Kaxiras, Phys. Rev. B, 2018, 98, 085406.

55 N. Takahashi, M. Nagao, A. Miura, S. Watauchi, K. Tadanaga, Y. Takano and I. Tanaka, J. Ceram. Soc. Jpn., 2018, 126, 591.

56 R. S. Mulliken, J. Chem. Phys., 1955, 23, 1997. 